Session 2793

\title{
A Student Design Program that Integrates Research, Education, and Community Service
}

\author{
Robert F. Erlandson, Ph.D. \\ Enabling Technologies Laboratory, Department of Electrical and Computer \\ Engineering, Wayne State University, Detroit, MI 48202
}

Introduction

The Enabling Technologies Laboratory (ETL) has created a unique student design program that not only complements and integrates a student's previous academic experiences, but also naturally integrates research, education, and community service into the student design activity. Developing such a program is difficult and requires a unique combination of institutional support, research interest, community support and involvement, and resources. The following will examine the role that each of these elements plays in creating the ETL student design experience. An overview of the student design process will be presented and the community impact of the student projects will be discussed.

Institutional Support and Research Interests

Institutional support for the ETL's student design program has come in the form of laboratory space and equipment, and most importantly, time to develop and grow the program. The ETL is part of the Electrical and Computer Engineering Department (ECE) in the College of Engineering at Wayne State University (WSU). The student design program offers a solid design experience for the students and concurrently supports the College's mission of teaching, research and outreach, and service to the region, state, and nation. ${ }^{1}$

The ETL conducts research on the impact and effectiveness of technologies that enhance human performance both physically and cognitively. The ETL also designs and develops products and processes to enhance human performance, with an emphasis on the needs of individuals with disabilities. Accessible design principles are key elements in these research and design activities.

Accessible design means to design processes, products, and services such that people with as broad spectrum of abilities as possible can access and use the processes, products, or services. Accessible design seeks to ensure physical accessibility through the use of sound human factors principles. In addition to physical accessibility, the design needs to provide cognitive accessibility-- that is, reduce memory requirements, computational demands, and possibly the elimination of reading requirements, so as to keep a process as simple as possible. Accessible design aids in reducing the variability associated with processes, jobs, and device performance by building in error-proofing and error-handling capabilities. 
Exposure to accessibility issues and accessible design principles are not typically part of the undergraduate engineering curriculum. One must not conclude that ethical considerations alone are the only reason for the inclusion of accessible design principles. ETL research shows that manufacturing concerns that focus on job productivity, quality, and safety are closely related to accessible design. ${ }^{2}$ Of course, legal mandates for the design of accessible products and the use of accessible design principles in the design process are, in their own right, compelling reasons to include accessible design principles in the undergraduate engineering curriculum.

The design of products must take into account the manufacturing and assembly processes associated with the products. Design for Assembly (DFA) and Design for Manufacturing (DFM) are strategies that address the fabrication issues. ${ }^{3,4}$ These strategies cover both physical and cognitive demands of the assembly and manufacturing processes and embody accessible design principles.

The advance of QS and ISO quality assurance processes and certification requirements are additional factors creating a need for a better understanding of accessible design principles. QS and ISO certification and compliance require the application of kaizen techniques and quality tools. ${ }^{5-7}$ Kaizen is a Japanese term meaning continuous improvement. In the United States it has come to be an umbrella term for a variety of quality improvement tools and techniques. ${ }^{7}$ Ergonomics, agile design, DFA, DFM, and process improvement principles are all part of the kaizen umbrella. ETL research has shown that these kaizen principles embody accessible design principles and thereby improve the job performance and create jobs for individuals with disabilities. ${ }^{2,8-10}$

Legal mandates come from a variety of laws that cover all engineering disciplines. These include the Americans with Disabilities Act (ADA), 1990, 11 the Telecommunication Act of 1996, Section 255, 12 and Section 508 in the Workforce Investment Act of 1998. 13 Together these laws mandate the accessibility for individuals with disabilities to buildings, facilities, jobs, public information and information required for the performance of a job, Internet and World Wide Web based activities, all telecommunication products and services, and all electronic and information technology (E\&IT) purchased and used by the federal government.

Further, the Individuals with Disabilities Act (IDEA) and the associated 1997 amendments mandate that the educational environment (K-12), including not only the physical plant, but also educational curriculum, materials and activities, be accessible to students with disabilities. 14 IDEA 97 also promotes the inclusion of students with disabilities into the general education environment. This law has had a significant impact on the ETL student design program.

\section{Community Support and Funding}

ETL is part of a consortium of eight Regional Educational Service Agencies (RESAs), representing eight counties in southeastern Michigan (termed Region IV). The RESAs provide professional development services to schools within their respective counties. ETL's role within the consortium is to provide technology, training, and support to help the schools more 
effectively comply with IDEA mandates and serve students with physical and cognitive disabilities.

As part of its research efforts to study the impact of accessible design principles on educational and vocational processes, the ETL works to train educators and associated professionals in accessible design principles and then works with them to implement these principles in their schools. Toward this end, the ETL has established a close working relationship with General Motors. Project Enable is a collaborative effort between the ETL and the GM Quality Network Group to train individuals from educational and vocational service professions in kaizen, process improvement, and quality control techniques. Since 1994 over a thousand people from the Region IV consortium, including both general education and special education teachers, Occupational, Physical and Speech therapists, school administrators, vocational rehabilitation specialists, and WSU engineering students, have been trained in kaizen and process improvement principles.

The majority of ideas for student design projects come from teachers working at schools within the participating Region IV schools. Project ideas also come from community businesses, outpatient clinics, and vocational service and job placement agencies. Individuals from a school, community business, clinic, or vocational rehabilitation service-job placement agency, attend one of the Project Enable workshops and become motivated to develop some of the ideas at their organization. ETL staff is invited to the facility to meet the staff and become familiar with the facility's operations and needs, and if appropriate, ETL personnel make one or more formal presentations. A small working group emerges from this process with some very specific needs for products and/or process changes. It is at this point that the coordinated student design efforts begin. The project ideas tend to be related to broader institutional objectives and not isolated events.

Another important objective of the ETL/Region IV collaboration is to create a process whereby good student project designs could be upgraded and made available to other schools within the participating counties. To accomplish these ends, Region IV provides support for a full-time engineer, an information specialist, part-time student assistants and funding for the redesign and replication of student design prototypes into demonstration systems that are available on loan to participating schools or sold to the participating schools.

In addition to support provided by Region IV, the ETL was awarded an NSF Bioengineering Student Design Grant to support the student design activities (BES-9707720). This grant has provided funding for supplies and materials for the student design projects as well as support for necessary laboratory design and testing equipment and development software. Business and industry have also been extremely supportive of our efforts with the donation of equipment and technical support.

\section{Student Design Program}

Student design projects typically take one of two forms--a single semester product or device design and implementation, or a multi-semester process redesign project. When the project is a device, the student design teams must develop a design, implementation, testing, and 
documentation schedule. ETL personnel and the student teams negotiate a schedule and outcomes that are reasonable for a semester timeframe. One of the first scheduled tasks is to translate the user's functional requirements into technical requirements and consider a number of alternative design strategies. These alternatives are presented to ETL staff and the client. From these discussions a preferred design is selected.

The students then create a working prototype that is field-tested in a host facility. At multiple stages during the design process the student teams actively solicit design input from the clients. Clients are encouraged to try out the device features as they are developed. The client testing can occur with low-fidelity models such as input/output displays drawn on a flip chart, or pseudo screens that simulate various actions and system response on a monitor, or cardboard models of the device showing the essential design features such as actual size and placement of control buttons, switches, connectors, the display area and size. Testing can also occur on the actual device as features are made ready. At some point in the semester the design freezes and the product is made ready for delivery.

The full-time engineer, information specialist, and a graduate student assistant work with Dr. Erlandson during the academic year to supervise and provide the necessary support for the student design groups. This team also ensures that a complete design portfolio is generated for each student project. The portfolio contains project documentation such as the final project report which summarizes the problem, user needs, technical requirements, and design objectives. For hardware projects the portfolio also contains schematics, part lists, costs, and printed circuit board layouts. For software projects, the portfolio contains source code that conforms to ETL coding standards; in particular, it contains embedded comments and user notes. Adequate documentation is an important component of the process and requires a structured, coordinated effort to ensure student compliance. The information specialist (a technical writer and the ETL webmaster) reviews the student portfolios and creates other documentation, including user manuals and other documentation for commercial products.

The ETL has the objective of creating products that can be replicated and utilized throughout the eight counties in Region IV. More often than not, the prototypes must be redesigned or modified before they can be replicated and distributed. If the modifications or redesigns are modest and do not represent a sufficient challenge for a full, four-credit hour design project, they might be suitable for a lesser credit hour directed study project, or the modifications may be done by ETL staff. If the redesign is significant, then the project enters a second student design phase where a second team has access to the original prototype, the field-test results and client interviews. Based on such user experience and input, a second-generation product is designed, implemented, and field-tested.

The multi-semester process reengineering projects provide the engineering students an opportunity to work closely with community organizations and representatives on a truly multidisciplinary, complex design problem. The Josephine Brighton Skills Center experience is presented as an example of the multi-semester projects. ${ }^{15}$

The Josephine Brighton Skills Center (Jo Brighton) is a vocational training center for special education students aged 16-26, operated by the School District of the City of Wyandotte, Wayne 
County, Michigan. The Center's mission is to provide education and vocational training to people with disabilities to help them attain their preferred life outcomes. To do this, the center provides vocational training in a variety of vocational classrooms in the center and worksites in the community. Between 1996 and 1999 seven student design projects were initiated at Jo Brighton--three dealing with the center's commercial bakery, three with their commercial kitchen, and one with their vocational preference selection process. ${ }^{15}$ These seven projects included four device projects and three process re-engineering projects.

After participating in the Project Enable Process Improvement Workshops, staff at Jo Brighton undertook a two-year (1995-1997) initiative to redesign the operations and layout of the commercial bakery. ETL staff played a consultative role in the effort. Coordinated with this redesign, staff requested two specific devices to help students weigh ingredients.

To assist students with cognitive disabilities to perform weighing tasks, a computer-based talking scale system was designed and built by an ECE student design team. Field-testing demonstrated the validity of the prototype system to function as a cognitive tool, but for a variety of technical reasons, it proved unreliable. Based on these field test results, a second version of the talking scale system was designed, implemented, and is now operational.

In order to allow students with physical disabilities to take part in bakery classroom activities, staff requested a switch operated flour/sugar dispensing system be incorporated with the talking scale system. A Mechanical Engineering student design team designed a switch-operated dispenser, which was integrated with the talking scale system. Field-testing again demonstrated the validity of the concept, but over time the dispensing mechanism proved unreliable. The dispensing system has been withdrawn from operation and is a candidate for redesign.

The results of the bakery classroom redesign were dramatic in terms of achieving the objectives of increased student independence, less involvement of teachers and staff in the baking operations, and more teacher and staff time spent on teaching universal work skills and bakeryrelated skills. ${ }^{10}$ An unplanned outcome was a dramatic increase in productivity. Cookie production in the center's commercial bakery went from an average of 300 dozen cookies per week before the redesign to an average of 700 dozen cookies a week after the redesign. 10

Based on the success of the bakery project, Jo Brighton staff undertook a redesign of their commercial kitchen. The kitchen project was designed to actively involve ETL personnel and students. Three engineering student groups took part in the kitchen re-engineering. In all cases, the engineering students were integrated into teams, which included Jo Brighton teachers and therapists. The project also included a consultant from General Physics, an international company that provides educational and training services in kaizen and process improvement techniques. Meetings were held on a regular basis with engineering student teams, WSU faculty, the General Physics consultant and Jo Brighton staff teams in attendance.

The first project (Winter 1998) involved an Industrial Engineering (IE) student design team and was an analysis and redesign of the kitchen classroom. Because the classroom is now organized using a visual structuring system, the students can set up, operate, and restock their workstations without having to read signs or rely upon supervisory input. The students are more empowered 
now, can complete tasks independently and, thus, staff has more time to teach other skills or help students who need additional instruction.

The second project, also conducted by IE student designers, is a commercial food preparation kit and grew from the process flow analysis conducted in project 1 . The kit, which keeps all of the tools necessary for each job in one contained unit, eliminates a great deal of the confusion and traffic involved with looking for and retrieving the tools for each task. Students can easily locate their kit, and with a quick visual scan, be certain that they have all of the tools needed to begin working. With this accommodation, the students are able to complete tasks quickly and have more time for learning new skills.

The third project, a computerized receipt creation program, enables students with limited reading skills to take and receive food orders. This project involved an ECE student design team. The computerized receipt system uses alternative keyboard entry hardware, picture icons, and voice prompts to allow the student taking the order to communicate effectively with the students receiving the orders in the kitchen. This tool has created jobs for workers who cannot write or hold a writing implement, as the previous method of logging customer orders involved circling an iconographic representation of the customer's order on a paper receipt. 15

The final Jo Brighton student design project addressed a much different problem at the center and illustrates the diffusion process of ideas and applications. The vocational guidance counselor, familiar with the ETL's work at Jo Brighton, approached the ETL about replacing a workbook approach to determining student vocational preferences. The workbook approach was a slow, awkward approach during which students often lost interest and thus, the approach was replaced with a computer-based selection process. The resulting Vocational Preference Analysis program allows the students to work independently at their own pace, conducts an automatic preference analysis, and provides a report to both the counselor and the student. The system can be used with a keyboard or mouse for selection, or it can be used with visual scanning and single switch technology for students who cannot use a keyboard or mouse.

The combination of these seven projects has provided for a highly accessible, error-free learning environment in which nearly all students have the capacity to participate. ${ }^{10}$ Personnel in two other classrooms, the commercial business and catering classrooms, are in the process of redesigning these rooms. We anticipate additional student design projects to grow out of these new initiatives.

\section{Results and Community Impact}

From a research perspective, our work has shown that the application of accessible design principles in special education classrooms has increased student independence, decreased behavioral problems, and thereby allowed teachers and staff to spend more time on teaching academics and universal work skills. 10,16 Further, in vocational settings, the application of accessible design principles has improved the work performance of and created jobs for individuals with disabilities. 2,89 
These results derive from the fact that application of the accessible design techniques creates environments that support competent participation. Through the use of sound ergonomic principles and the creation of environmental cognitive supports that use visual control, standardized work, and workplace organization, the environment literally supports the worker and the student to "do the right thing."

In addition to providing the engineering students a wide range of challenging projects, the ETL student design program introduces engineering students to accessible design principles, as well as the needs and capabilities of individuals with disabilities. The student design program provides technical resources and expertise to organizations that otherwise would not have access to them, and it enables the utilization of accessible design principles in community settings. Thus, the program creates opportunities to educate the community as to the benefits and possibilities of the win-win scenarios described above. The student design program creates viable demonstrations and pilot study cases showing the efficacy of the application of accessible design principles. In these ways, the ETL's student design program integrates research, education, and community service into a unique student design experience.

Ms. Judith Phelps, the Region IV/ETL liaison from Wayne RESA has summarized the ETL's contributions as follows: "ETL integrates the student design projects into a broader context than simply a collection of successful individual projects. ETL brings together resources from various fields of expertise, including business, manufacturing, the rehabilitation community and school systems. ETL provides an extremely valuable resource to our region by coordinating and synthesizing these resources. The student design projects, which primarily focus on vocational needs, are developed as part of this extensive knowledge base, thereby enriching the experience for both the engineering students and the community partners." 17

When the ETL student design program started it was important to establish a reputation, attitude, and expectations for excellence and quality among the students, participating faculty, and collaborators from the community. As such, participation in the RESNA Easter Seal Student Design Competition was encouraged. During its first two years of operation ETL students entered six design projects and had three winners. ${ }^{18-20}$

The Keith Bovenschen School, located in Warren, Michigan, and part of the Macomb Intermediate School District, is a facility that serves about 200 severely impaired students through age 26 and is another Region IV demonstration site that deserves attention for its impact on the community. Bovenschen staff, like Jo Brighton staff, were among the very first to take advantage of professional development training opportunities offered by the Region IV, ETL and GM collaborations. Bovenschen staff aggressively implemented kaizen techniques. ETL personnel and Wayne State University engineering students have worked with the Bovenschen staff on a variety of projects since 1993.

In recognition of Bovenschen's creativity and dramatic educational results, Bovenschen received the Michigan Association for School Boards 1997 Education Excellence Award. ${ }^{21}$ Additionally the Macomb Intermediate School District, Clinton Township, Michigan, received the Magna 2000 Award. ${ }^{22}$ Magna Awards were initiated in 1995 by the American School Board Journal to 
"recognize local school boards for taking bold and innovative steps to improve school district governance and make a positive impact on student learning." 23

Most recently, the ETL was awarded the 2000 Michigan Campus Compact Faculty/Staff Community Service-Learning Award. This award is given to recognize exceptional programs at the 31 participating Michigan colleges and universities, that "engages or influences students to be involved in community service or service-learning through modeling, influence or instruction." 24

\section{Conclusions}

The results seen at Jo Brighton are being replicated throughout the eight counties in southeastern Michigan. The Jo Brighton examples drive home an important point, which is that well-designed projects take time. The dramatic and positive impact we are seeing today with respect to the delivery of educational services at these schools evolved over a five to six year period. Longterm, sustained support for the activities is crucial. The ETL program is entering its sixth year of sustained support from the Region IV Consortium and is starting its fourth year of NSF support from the Biomedical Engineering student design program. This consistent, sustained support has allowed people to make long-term plans with the confidence that their hard work will reach a conclusion and not be cut short for lack of funding. The sustained support has lead to consistent staffing which has allowed strong, trusting, working relationships to develop over the years. This is a powerful win-win situation.

\section{Acknowledgements}

I would like to acknowledge the financial support of the eight Region IV Intermediate School Districts: Jackson, Lenawee, Macomb, Monroe, Oakland Schools, St. Clair, Washtenaw, and Wayne RESA, two NSF grants: BSE 9707720, from the Bioengineering/Rehabilitation Program for Student Design Projects and DUE 9972403, for development of accessible design curriculum material. I would also like to acknowledge the support of the teachers and administrators from all the participating schools, my colleagues at Wayne State University, and special thanks to Kristine Bradow and Krysta Stone, ETL Information Specialists, and especially David Sant, ETL Engineer, whose technical expertise and instructional skills helped make this such a successful endeavor.

\section{References}

1. Wayne State University. About Wayne State University (http://www.wayne.edu/about_wayne2.html, 1999).

2. Erlandson, R. F., Kierstein, I. \& McElhone, D. in Council on Exceptional Exceptional Children - Annual State Conference (Grand Rapids, MI, 1998).

3. Boothroyd, G. \& Dewhurst, P. Product Design for Assembly (Boothroyd Dewhurst, Inc, Wakefield, RI, 1991).

4. Crow, K. A. Design for Manufacturability: It's Role in World Class Manufacturing (Defense Resource Management Associates, Palos Verdes Estates, CA, 1989).

5. Hoyle, D. QS 9000 Quality Systems Handbook (Butterworth-Heinemann, Newton, MA, 1997).

6. Randal, R. C. Randall's Practical Guide to ISO 9000: Implementation, Registration, and Beyond (AddisonWesley, Reading, MA, 1995).

7. Imai, M. Gemba Kaizen (McGraw-Hill, New York, New York, 1997). 
8. $\quad$ Erlandson, R., F, Noblet, M., J \& Phelps, J., A. Impact of Poka-Yoke Device on Job Performance of Individuals with Cognitive Impairments. IEEE Transactions on Rehabilitation Engineering 6, 269-276 (1998).

9. Erlandson, R. F. \& Sant, D. Poka-Yoke Process Controller Designed for Individuals with Cognitive Impairments. Assistive Technology 10, p102-112 (1998).

10. Powell, K., Hardin, S. \& Erlandson, R. F. in Closing the Gap (St. Paul, MN, 1998).

11. Access Board. Americans With Disabilities Act Accessibility Requirements (http://www.accessboard.gov/bfdg/adares.htm, Washington, D.C., 1999).

12. FCC. Access to Telecommunications Service, Telecommunications Equipment and Customer Premises Equipment by Persons with Disabilities. Federal Register 64, 63235-63258 (1999(b)).

13. Electronic and Information Technology Access Advisory Committee. Final Report of the EITAAC. http://www.access-board.gov/pubs/eitaacrpt.htm (1999).

14. OSERS. IDEA97 Regulations. http:/www.ed.gov/offices/OSERS/IDEA/regs.html (1999).

15. ETL. The Jo Brighton Skills Center (http://ece.eng.wayne.edu/etl/design/jobrighton.html, 2000).

16. Erlandson, R. F., Greenwood, L., Perrin, M. \& Zapinski, R. in The National Governor's Conference: Quality in the Classroom (Dearborn, MI, 1997).

17. Phelps, J. A. (2000).

18. Cooney, B., Marigomen, D. C., Wassick, G., Sant, D. \& Auusiem, O. in Proceedings of the RESNA 94 Annual Conference p546-548 (RESNA Press, Washington, D.C., 1994).

19. Deal, L., LoPorto, J. \& Rippy, J. in Proceedings of the RESNA 93 Annual Conference p557-559 (RESNA Press, Washington, D.C., 1993).

20. Loss, R., Zarewych, D. \& Gilbert, K. in Proceedings of the RESNA '94 Annual Conference p555-557 (RESNA Press, 1994).

21. 1997, E. E. A. Michigan Association for School Boards (, 1997).

22. American School Board Journal. Magna Winners 2000 (http://www.asbj.com/magna/contents.html, 2000).

23. American School Board Journal. About the Magna Awards (http://www.asbj.com/magna/about.html, 2000).

24. Michigan Campus Compact. About the Michigan Campus Compact (http://www.mcc.mna.msu.edu/about.htm, 1998).

Robert F. Erlandson

Robert F. Erlandson is Director of the Enabling Technologies Laboratory at Wayne State University, Detroit, Michigan. Dr. Erlandson received a B.S. degree in Electrical Engineering from Wayne State University and a Ph.D. in Biomedical Engineering from Case-Western Reserve University in 1970. Before joining Wayne State University in 1976 he worked at Bell Telephone Laboratories where he was actively involved in their "In-Hours Continuing Education Program" and worked in the Advanced Software Systems Group. From 1985 to 1990 he was on loan from the university to serve as Vice President for Research and Technology Development for the Metropolitan Center for High Technology, one of three economic development centers established by the State of Michigan. Dr. Erlandson's interest in accessible design issues grew out of his design experiences and work in the area of rehabilitation engineering. 